\title{
Enfoque ético-jurídico de la sentencia de la Corte Suprema de los Estados Unidos sobre patentabilidad de genes humanos
}

\author{
Salvador Darío Bergel
}

\section{Resumen}

El artículo discute aspectos ético-jurídicos de la sentencia de la Corte Suprema de los Estados Unidos (EUA) sobre la patentabilidad de los genes humanos, en juzgamiento ocurrido en Junio de 2013. Presenta los antecedentes del caso bien como, en líneas generales, sitúa el debate actual sobre la patentabilidad genética humanos. La discusión informa acerca del conflicto judicial desarrollado en los EUA en virtud de posiciones distintas y discrepantes sobre la cuestión de las patentes, estableciendo comentarios a la decisión de la Corte. Delante de los hechos y argumentos presentados la conclusión critica la sentencia, demostrando que la propiedad industrial está en el centro de las negociaciones sobre patentes y que la presión de los intereses comerciales sobrepuja hasta mismo los valores humanos.

Palabras-clave: Ética. Genética. Comercialización de productos-Genes. Juicio-Estados Unidos. Legislación como asunto-Comercio.

\section{Resumo}

\section{Enfoque ético-jurídico da sentença da Suprema Corte estadunidense sobre patentes de genes humanos}

$\mathrm{O}$ artigo discute aspectos ético-jurídicos da sentença da Suprema Corte dos Estados Unidos (EUA) sobre patenteamento de genes humanos, em julgamento ocorrido em junho de 2013. Apresenta os antecedentes do caso, bem como, em linha gerais, situa o debate atual sobre a patentabilidade genética humana. A discussão informa acerca do conflito judicial nos EUA em decorrência de posições distintas e discrepantes sobre a questão patentária, comentando a decisão da Corte. Diante dos fatos e argumentos apresentados a conclusão critica a sentença, demonstrando que a propriedade industrial está no centro das negociações sobre patentes e que a pressão dos interesses comerciais sobrepuja até mesmo os valores humanos.

Palavras-chave: Ética. Genética. Comercialização de produtos-Genes. Julgamento-Estados Unidos. Legislação como assunto-Comércio.

\begin{abstract}
Ethical-legal approach to the judgment of the Supreme Court of the United States on the patentability of human genes

The article discusses ethical and legal aspects of the judgment of the Supreme Court of the United States (U.S.) on the patentability of human genes in trial occurred in June of 2013. Presents the background of the case as well, in general, places the current debate on human genetics patentability. The discussion reports on the judicial conflict developed in the U.S. under different and conflicting positions on the issue of patents, establishing commenting on the decision of the Court. Ahead of the facts and arguments conclude criticizes the judgment, showing that industrial property is at the center of negotiations on patent and pressure surpasses commercial interests to the same human values.

Key words: Ethics. Genetics. Products commerce-Genes. Judgment -United States. Legislation as topicCommerce.
\end{abstract}

Doutor s.bergel@zbv.com.ar - Universidad de Buenos Aires (UBA), Buenos Aires, Argentina.

\section{Correspondência}

Calle Florida 537 piso $18^{\circ}$ C1005AAK. Buenos Aires, Argentina.

Declara não haver conflito de interesse. 
Tal vez pueda llamar la atención que en una publicación sobre temas bioéticos se aborde una decisión judicial que resuelve un conflicto suscitado en el campo de la propiedad industrial. Es que en el curso de las últimas décadas, ha operado una profunda transformación en los fines y métodos del derecho de propiedad industrial. En su concepción tradicional el derecho de patentes - piedra angular de los derechos de propiedad industrial - se refería a objetos y procedimientos técnicos, lo que lo apartaba de los temas éticos.

Con la evolución de los tiempos el derecho de patentes sufrió el embate del mercado, lo que hoy posibilita, sin llamar la atención de nadie, la incorporación de los problemas y dilemas éticos. La inusitada extensión de sus dominios a temas jamás imaginados impone esta consideración. La patentabilidad de seres vivos, de procesos biológicos, de información genética, de células y líneas celulares, de semillas, de microorganismos y hasta de mamíferos, no puede ni debe ser estudiada sin advertir el impacto ético que provoca. En este encuadre la idea tradicional de que la propiedad industrial y la ética transitaban por carriles distintos y alejados, queda desbordada por los datos de la realidad.

En el informe que produjo el Consejo de Estado Francés sobre la reforma a las leyes de bioética, se hizo hincapié en la necesidad de contemplar aspectos éticos relevantes. Es que resultaba ajeno a la realidad ubicar a la propiedad industrial y a la ética en compartimentos estancos, lo que sólo serviría para justificar los abusos que encierran los derechos de la propiedad industrial en el presente ${ }^{1}$. Hoy resulta incuestionable el enfoque ético en esta materia, especialmente cuando hablamos de patentes vinculadas con el ser humano.

Prueba palpable de ello es que la Directiva Europea 98/44/C sobre protección de las innovaciones biotecnológicas - el instrumento más completo que se haya elaborado en este campo - inicialmente no contenía previsiones éticas. En el largo camino que demandó su aprobación - casi un decenio - se fueron incorporando normas sobre este particular y finalmente sobre los dieciocho artículos que la conforman, siete contemplan aspectos éticos. El tema que consideramos viene dado desde los comienzos del Proyecto Genoma Humano. Hace más de dos decenios, al instalarse la Cátedra de Derecho y Genoma Humano en la Universidad de Deusto, por iniciativa de Carlos María Romeo Casabona, se celebró un importante evento internacional en el que - entre otras materias - se debatieron las cuestiones éticas que ya se avizoraban sobre la patentabilidad de genes humanos.
Desde entonces, el crecimiento exponencial de las patentes otorgadas en este campo suscitó un duro debate sobre su procedencia ética y legal, debate que aún no se puede dar por concluido. En los Estados Unidos los tribunales de justicia justificaron con diversos argumentos la patentabilidad, pero la creciente presión de sectores científicos y representativos de la sociedad civil llevó el tema a los estrados de la Corte Suprema. La decisión, largamente esperada por el prestigio y la influencia que este tribunal tiene en el mundo, es desalentadora ya que ratifica en lo sustancial las políticas sostenidas hasta ese entonces.

Tales antecedentes me movieron a comentar esta decisión que - a primera vista - pareciera cambiar el rumbo, pero que en un análisis más profundo lleva a reiterarlo una vez más.

\section{Antecedentes}

Resulta interesante examinar los antecedentes del caso para poder apreciar en toda su magnitud lo que estaba en juego. Los litigios que se suscitaron tanto en los Estados Unidos como en la Unión Europea contra Myriad Genetics tuvieron como centro las patentes otorgadas sobre dos genes de predisposición al cáncer de mama y de ovario: el BCRA1 y el BCRA2 . En las personas sanas, ambos genes son supresores de tumores que ayudan a regular la división celular. Se cree que las formas mutadas de estos genes son responsables de la mitad de los casos de cáncer de mama hereditarios, especialmente de los que se presentan en mujeres jóvenes. Las mujeres con mutaciones en cualquiera de estos dos genes tienen un riesgo mayor de desarrollar cáncer de mama y de ovario que las mujeres con las versiones "normales" de los genes ${ }^{2}$.

El primero de estos dos genes fue localizado en el cromosoma 17 por investigadores de la Universidad de Berkley en diciembre de 1990. Advirtiendo las implicancias económicas que tendría el hallazgo, Mark Skolnick fundó la sociedad Myriad Genetics, la que formalizó una alianza con la Farmacéutica Eli Lilly a fin de continuar con las investigaciones tendientes al aprovechamiento comercial del hallazgo, lo que llevó a clonar y a patentar el gen. Un segundo gen implicado en el cáncer de mama fue identificado en 1995 por un consorcio de laboratorios públicos europeos, estadunidenses y canadienses piloteado por investigadores británicos del Instituto de Investigaciones sobre Cáncer de Londres y el Centro de Genómica Sanger de Cambridge. Este hallazgo motivó 
la solicitud de varias patentes por parte de universidades norteamericanas con el propósito de valorizar económicamente los conocimientos adquiridos; así como por parte de investigadores del consorcio europeo que perseguían garantizar el libre acceso a la información genética.

Una federación de ayuda a las investigaciones sobre cáncer ofreció su colaboración a los laboratorios ingleses de la Cancer Research Company, la que solicitó las patentes sobre el segundo gen BRCA2 en 1995 y; obtenida, concedió una licencia para su utilización comercial a Oncormed, competidora de Myriad Genetics, para contener las ya manifestadas intenciones monopólicas de ésta. La situación ocasionada por la coexistencia de patentes referidas a los genes BRCA1 y BRCA2 entre firmas competidoras concluyó en 1998 con la concentración de las patentes de ambos genes en manos de Myriad Genetics ${ }^{3}$.

Con otras ocho patentes relacionadas con los referidos genes, Myriad Genetics dispuso de un monopolio muy extendido sobre el conocimiento y las aplicaciones de los genes de predisposición al cáncer de mama. Cabe aquí resaltar que las patentes concedidas son muy amplias en cuanto cubren toda reproducción de la secuencia de ADN y todos los productos que derivan de ella (sondas, anticuerpos, animales transgénicos portadores de alelos alterados, etc.); y todo método diagnóstico de predisposición al cáncer de mama, tanto como las aplicaciones a los fines terapéuticos o "screening". Las reivindicaciones no contienen limitaciones en cuanto a las técnicas utilizadas con el fin de mostrar una mutación de la secuencia de los genes comprometidos ${ }^{3}$.

Paralelamente Myriad Genetics solicitó y obtuvo de la Oficina Europea de Patente similares títulos. En poder de una cartera de patentes relacionadas con dichos genes, orientó su accionar en dos direcciones: la utilización terapéutica - tema de mayor complejidad -; y la utilización para uso diagnóstico, tema menos complejo y más redituable ${ }^{4}$. Los derechos para usos terapéuticos fueron negociados con firmas farmacéuticas y se reservó en forma exclusiva el ámbito diagnóstico, lo que le brindó cuantiosas utilidades a través de la creación de una división dedicada exclusivamente a acaparar a nivel mundial la prestación de tales servicios.

Con sus patentes Myriad Genetics, que había exigido que todos los test diagnósticos fueran efectuados en sus laboratorios de Salt Lake City, se aseguró el monopolio mundial, que fue calificado en los planos ético y económico como escandaloso ${ }^{5}$. La utilización monopólica de los exorbitantes dere- chos acordados por las patentes ponía en peligro el resguardo de la salud de las poblaciones, lo que motivó el accionar de instituciones públicas para anular las patentes o en su caso poder limitarlas en términos razonables. Francis Collins anota que Myriad ha protegido con uñas y dientes los derechos que se derivan de su patente, denunciando a cualquier laboratorio que intente ofrecer estos análisis. Todas las otras empresas que han intentado hacer esta prueba diagnóstica en los Estados Unidos se han visto obligadas a abandonar el negocio. Myriad ostenta un monopolio absoluto sobre una prueba que hoy desean hacerse muchas mujeres con una historia familiar de cáncer de mama o de ovarios. La falta de competencia del mercado ha mantenido su precio bastante elevado (alrededor de US\$3,500), fuera del alcance de muchas personas a las que les gustaría tener esa información ${ }^{6}$.

Los términos en los que fue elaborada la sentencia aquí comentada permiten deducir - en el tema central que involucra la protección de la salud pública - que las patentes de Myriad siguen vigentes, lo que lleva a sostener que puede continuar siendo la única empresa autorizada para proporcionar las pruebas genéticas para el cáncer de mama y ovario. Esto amenaza con nuevos litigios, en tanto Myriad presentó demandas por infracción a sus derechos contra dos empresas que habían anunciado que comenzarían a ofrecer pruebas de menor costo para detectar los genes vinculados con el cáncer de mama y ovario. Esto llevó al Presidente del Comité Jurídico del Senado a instar a los Institutos Nacionales de Salud (NIH) a utilizar los march-in rights, derechos que se ponen en marcha en los casos en que la investigación entre dentro de los alcances de la Ley Bayh-Dole (financiación pública) y que conduciría a exigir a la accionada a conceder licencias en "términos razonables" 7 .

En Europa accionaron por la nulidad de las patentes la Federación Nacional de Centros de Lucha contra el Cáncer, la Federación de Hospitales de Francia, la Sociedad Belga de Genética Humana, la Sociedad Alemana de Genética y similares instituciones danesas, checas, suizas, austríacas, italianas, finlandesas y británicas, obteniendo una limitación considerable en las reivindicaciones otorgadas. En los Estados Unidos accionaron por nulidad numerosas instituciones científicas y el Departamento de Justicia se presentó en el proceso como amicus curiae, alegando que lo debatido era de gran importancia para la economía nacional, las ciencias médicas y la salud pública. 
El debate sobre la patentabilidad de genes humanos

En 1988 las oficinas que manejan las patentes en el mundo, USTPO (norteamericana), EPO (de la Unión Europea), y JPO (de Japón), emitieron un comunicado conjunto unificando criterios sobre el tema central del debate que se avecinaba, en el que sentaron la siguiente doctrina: los productos naturales purificados no son considerados productos naturales o simples descubrimientos, en tanto no existen en la naturaleza en forma aislada ${ }^{8}$. Léase en buen romance que la simple tarea de aislar el producto natural lo torna "apropiable" por vía de los derechos de propiedad industrial.

Cuando a consecuencia del avance del Proyecto Genoma Humano se desató la batalla por el dominio de los genes y con ello de la información genética que portan, se impuso este criterio: las secuencias de ADN aisladas de su medio no dejan de ser patentables en tanto se considera que constituyen un "producto industrial" y no una mera sustancia natural. Es claro que el carácter informativo de los genes, traducido en el hecho de ser portadores de información genética, no puede conducir a su patentabilidad. No es posible ni razonable que alguien someta a su dominio alguna información que pertenece al mundo natural y que simplemente es revelada al supuesto "inventor" a través de los procedimientos de aislamiento y purificación, sin que exista modificación del mundo externo.

En esta dirección, observa Tallacchini, que el aislamiento y la purificación se han convertido en el criterio científico legislativo para presumir que legalmente los materiales biológicos se han transformado en artefactos patentables ${ }^{9}$. Conforme a este criterio una patente sobre un nuevo "producto químico" - el genv - cubre todos los usos, hayan o no sido descriptos por el titular. En su momento Barton criticó esta postura entendiendo que no está claro que sea sabio aplicar tales principios legales de base química al contexto genómico ${ }^{10}$. Kahn - eminente biólogo francés - marca la especificidad del gen en este terreno. Un gen - enseña - puede ser sintetizado químicamente a partir de sus constituyentes de base, es decir los nucleótidos. Sin embargo, comparado con otras moléculas inertes del mundo biológico, por ejemplo las enzimas, el ácido úrico, una proteína, una albúmina etc., los genes poseen una propiedad complementaria que hace a su especificidad: constituye el soporte de un programa genético ${ }^{11}$.
Para tornar viables las políticas de patentabilidad seguidas por la USTPO y compartidas por otras oficinas centrales, fue necesario definir la "invención" de la secuencia genética como la operación que consiste en aislarla de su ambiente natural o reproducirla por un procedimiento técnico. Esta definición - enseña Cassier - ensancha el campo de la invención, justificado por la intervención del hombre sobre la naturaleza. Es aquí donde finalmente se ubica el "inventor". Es decir, la intervención del hombre sobre la naturaleza concretada en aislar esta secuencia de un medioambiente más complejo para colocarla en un ambiente diferente.

La operación que consiste en aislar, manipular y reproducir los hechos naturales y los objetos naturales es la definición misma de la actividad del laboratorio. Por lo tanto, de esta forma, la distinción entre el trabajo de descubrir una sustancia natural y la invención de un artefacto se desvanece: Todos los productos de laboratorio fruto de los trabajos de descubrimiento serán potencialmente patentables, por poco que satisfagan los criterios clásicos de patentabilidad $^{12}$. Al margen de estas consideraciones y descendiendo al campo ético, entendemos que los genes como elementos integrantes del genoma, portadores de información genética no pueden ser apropiados, tal como lo sostuve desde hace largo tiempo ${ }^{12-15}$.

El genoma - ha dicho la UNESCO en una de sus brillantes declaraciones - es la base de la unidad fundamental de todos los miembros de la familia humana y del reconocimiento de su dignidad intrínseca y de su diversidad ${ }^{16}$. No es esta una descripción vacía de contenidos ni una frase de circunstancias; el genoma caracteriza a la especie. Todos los seres vivos están sometidos a un mismo código genético, pero la información genética de cada especie es la que lo determina, haciendo que la especie humana sea distinta de un ave, de un microorganismo o de un nogal. Esto viene dado por la naturaleza y acompaña a cada miembro de la especie durante toda su vida.

Someter a tal información a los avatares del derecho de la propiedad industrial es absurdo. Pareciera como muy aventurado sostener que alguien es titular de la información genética de la especie o en particular de la que porta un segmento de ella (el gen).

\section{El conflicto judicial en los Estados Unidos}

La nulidad de las patentes de Myriad fue demandada por un grupo de diversas entidades, entre ellas la American Civil Liberty Union, por ante los tri- 
bunales del Distrito de Manhattan en el año 2009. En marzo de 2010 el Juez Robert Sweet acogió la demanda y declaró nulas las patentes argumentando que los genes son importantes por la información que transmiten y que un gen aislado no es en realidad diferente a un gen contenido en el cuerpo. Apelada la resolución ante la Corte del Circuito Federal, ésta se pronunció en la fecha de 29 de Julio de 2011 revocando en todas sus partes la sentencia.

En la decisión de la Corte del Circuito Federal (segunda instancia) se tocaron sustancialmente dos temas: a) la patentabilidad del ADN genómico; b) la patentabilidad del ADNc (complementario). Con relación al primer punto se produjo una disidencia, ya que los Jueces Lourie y Moore se inclinaron por sostener su patentabilidad, siguiendo la corriente dominante; en tanto Bryson, en un extenso voto, se pronunció por la negativa. Los argumentos de la mayoría pueden sintetizarse así:

- No se ha patentado un gen humano, sino algo diferente: un gen aislado que difiere del gen nativo porque el proceso de extracción produce cambios en su estructura molecular (aunque no en su código genético);

- Los "productos naturales purificados" tienen características distintivas diferentes comparadas con el producto impuro, lo que resulta de significativa utilidad potencial. Las secuencias de ADN aisladas tienen propiedades muy diferentes que son directamente responsables de una nueva y significativa utilidad;

- Debido a que la diferente estructura química del ADN aislado es un producto de la intervención del hombre, ello conduce a una utilidad diferente y beneficiosa. En razón de ello se considera que los pequeños fragmentos de ADN aislados constituyen materia patentable.

El voto de Bryson, en disidencia, comienza por destacar que la esencia del argumento de Myriad es que no se ha patentado un gen humano, sino algo muy diferente, un gen humano aislado, que difiere del gen natural en cuanto el proceso de extracción produce cambios en su estructura molecular (aunque no en su código genético). En orden a aislar el gen BRCA es necesario romper los lazos químicos que sostienen el gen en su sitio en el cuerpo, pero el código genético secuencial que es el sujeto de cada una de las reivindicaciones del gen BRCA se mantiene igual, ya sea que el gen esté en el cuerpo o separado del mismo.

Si fuésemos a aplicar la nomenclatura convencional de algún campo para determinar si las reivindicaciones del ADN aisladas por Myriad son "nuevas" - observa - parece tener mayor sentido mirar a la genética que es el lenguaje de las reivindicaciones, más que a la química. Desde el punto de vista de la genética esa reivindicación abarca una "composición de materia", el gen BRCA1. Los genes aislados BRCA son idénticos a los genes BRCA encontrados en los cromosomas 13 y 17. Ellos tienen la misma secuencia, codifican las mismas proteínas y representan las mismas unidades de herencia.

Es verdad que las moléculas objeto de reivindicaciones han sido escindidas y ellas poseen terminales que difieren de aquellas que se encuentran en los genes que se generan naturalmente. La mayoría - anota - le da una significación a este hecho; pero la función de las moléculas aisladas de ADN es atribuible no a la naturaleza del proceso de aislamiento o a la identidad de los cuerpos terminales en las moléculas; la función de las moléculas que se reivindican es dictada por la secuencia de nucleótidos del gen, lo que aparece exactamente en el ADN aislado objeto de las reivindicaciones. La única diferencia entre los genes BRCA que se generan naturalmente y los aislados, objeto de reivindicaciones, es que éstos han sido aislados de acuerdo con los límites predefinidos por la naturaleza. En este sentido extraer un gen es similar a cortar una hoja de un árbol. Aun arrancando la hoja antes de tiempo no se volvería una invención humana.

Desde otro ángulo de mirada, recuerda que la mayoría del tribunal da un peso significativo al hecho que los segmentos codificados de los genes naturales reivindicados son parte de una molécula mucho más grande y que los genes aislados BRCA, siendo moléculas más pequeñas extraídas de una más grande constituyen invenciones hechas por el hombre. Pero - refuta Bryson - el argumento de que el gen aislado BRCA es patentable porque su entorno natural forma parte de una estructura mucho mayor no es más persuasivo que argumentar que no obstante que un átomo no puede ser patentable, una partícula subatómica sí lo es porque fue antes parte de una estructura mayor o que un árbol no es patentable, pero una rama sí lo es cuando es extraída del árbol.

Por último destaca que la escisión de enlaces covalentes que inciden en el aislamiento, en sí mismo no es una invención, y el hecho que las moléculas separadas tengan grupos terminales que difieren de las secuencias de nucleótidos que ocurren naturalmente, no agrega ningún carácter inventivo a las moléculas objeto de reivindicaciones. La porción funcional de la composición - la secuencia de nu- 
cleótidos - permanece idéntica al gen que produce la naturaleza. Los anotados argumentos de Bryson son muy sólidos no dejando dudas de que los genes genómicos reivindicados por la accionada no son patentables. En lo referente a la segunda cuestión planteada, la patentabilidad del ADNc, los tres vocales coincidieron en avalarla.

\section{La decisión motivo de este comentario}

Apelada la sentencia en la fecha de 20 de marzo de 2013, la Corte Suprema dictó el fallo que comentamos. En su decisión la Corte por unanimidad se pronunció acogiendo la demanda en cuanto a la no patentabilidad de los genes genómicos, y rechazó los argumentos de los actores en el caso del ADNc.

Luego de referirse a los antecedentes del caso, la Corte entró de lleno en el primer tema (patentabilidad de los genes genómicos por el sólo hecho de ubicarlos, secuenciarlos y aislarlos).

Es indiscutible - señala la Corte - que Myriad no creó ni modificó la información genética codificada en los genes BRCA1 y BRCA2. La ubicación y el orden de los nucleótidos existían en la naturaleza antes que Myriad los hallara. Myriad tampoco creó ni alteró la estructura genética del ADN. En cambio, la principal contribución de Myriad fue descubrir la ubicación exacta y la secuencia genética de los genes BRCA1 y BRCA2 dentro de los cromosomas 17 y 13. La pregunta es si esto hace que los genes sean patentables.

Myriad reconoció que la decisión de la Corte en el caso Chakrabarty es fundamental para esta indagación. En Chakrabarty los científicos agregaron cuatro plásmidos de una bacteria, lo que permitió degradar componentes de petróleo crudo. El tribunal sostuvo entonces que la bacteria modificada era patentable. Expresó que la reivindicación de la patente no lo era para un fenómeno natural desconocido, sino para un producto no natural o composición de materia - un producto del ingenio humano - que tiene nombre, características propias y un uso distintivo.

La bacteria de Chakrabarty era nueva con características marcadamente diferentes de cualquier otra presente en la naturaleza, debido a los plásmidos adicionados y a la consiguiente capacidad para degradar petróleo. En este caso - señala el tribunal - por el contrario, Myriad no ha creado nada. Sin duda encontró un gen importante y útil, pero separar el gen de su material genético o circundante no es un acto de invención. El revolucionario descubrimiento - innovador e incluso brillante en sí - no sa- tisface los requisitos del Artículo 101.

Recuerda igualmente la decisión precedente del Tribunal en el caso Frank Brothers Seed Co. vs. Kalo Inoculant Co., en el caso en el que se pretendió patentar una composición de bacterias sin alteración alguna. Sostuvo en esa oportunidad que la composición no era patentable porque el solicitante no alteró bacteria alguna. Por lo tanto la solicitud cayó de lleno en la excepción de producto natural. Lo mismo - agrega - ocurre con Myriad. Myriad halló la ubicación de los genes BRCA1 y 2 pero ese descubrimiento por sí mismo no convierte a los referidos genes en una composición de materia con derecho a una patente. Ello explicó que la ubicación del gen era desconocida hasta que la encontró entre los aproximadamente 8 millones de nucleótidos contenidos en una parte del cromosoma 17.

Muchas de las descripciones de la patente de Myriad simplemente detallan el paso "interactivo" del descubrimiento por el cual Myriad redujo los lugares posibles para las secuencias que buscaba. Myriad intentó vincular esos grandes esfuerzos de investigación a los supuestos de patentabilidad del Artículo 101. Pero - agrega la Corte - sólo el gran esfuerzo no es suficiente para satisfacer las demandas de tal requisito. Las reivindicaciones de Myriad - agrega - tampoco son suficientes por el hecho que el aislamiento de ADN a partir del genoma humano rompe los enlaces químicos y de ese modo crea una molécula natural. Simplemente las reivindicaciones no están expresadas en términos de una composición química, ni se basan de modo alguno en los cambios químicos que resultan del aislamiento de una sección particular del ADN.

En cambio las reivindicaciones se centran en la información genética codificada de los genes BRCA1 y BRCA2. En nota complementaria, luego de transcribir la primera parte de las reivindicaciones de la accionada, la Corte concluye su opinión sobre este particular: No obstante, el uso repetido de la expresión presente invención por Myriad, se desprende del texto de la patente que los diversos descubrimientos son la invención ${ }^{17}$. Los argumentos de la Corte sobre la no patentabilidad de los genes genómicos son incontestables complementando y reafirmando cuanto expresara Bryson en el voto en minoría en la Corte del Circuito Federal.

\section{La patentabilidad del ADNc}

Esta parte de la sentencia es, a mi criterio, la más relevante, ya que en unos pocos renglones pre- 
tende la Corte fundamentar la patentabilidad del ADNc. El ADNc (complementario) es una molécula del tipo ADN recompuesta a partir de la molécula de ARN "producido" por el gen. El gen en efecto contiene, además de la codificación de los ácidos aminos constitutivos de la proteína, las informaciones que conciernen a la regulación de la transcripción; informaciones que hacen que el gen sea operativo ${ }^{18}$. Acerca del tema dice el tribunal:

El ADNc no presenta los mismos obstáculos a la patentabilidad que los segmentos aislados de ADN natural. Como ya se explicó, la creación de una secuencia de ADNc a partir del ARNm resulta en una molécula de sólo exones, que no es de origen natural. Los peticionarios admiten que el ADNc difiere del ADN natural en que las regiones no codificantes se han eliminado. Ellos argumentan sin embargo que no es patentable el ADNc porque la secuencia del nucleótido del ADNc está dictada por la naturaleza y no por el técnico de laboratorio. Puede que sea así, pero el técnico de laboratorio, sin duda, crea algo nuevo cuando se hace ADNc. El ADNc conserva los exones del ADN natural pero es distinto del $A D N$ del cual deriva. Como resultado, el ADNc no es un "producto de la naturaleza" y es patentable en virtud del Art. $101^{17}$.

El análisis del tema planteado nos conduce a repasar algunos conceptos básicos de biología. El ADN es una macromolécula informativa compuesta, dentro de la cual se pueden distinguir una serie de subelementos llamados secuencias o regiones a las cuales les son atribuidas funciones particulares ${ }^{19}$. Presentada como un concepto de genética molecular, la información genética se define como el conjunto de los mensajes hereditarios contenidos en el material genético codificante para todas las estructuras y para su funcionamiento ${ }^{20}$. Desde el punto de vista evolutivo para que algo (una fuente) contenga o porte información debe existir precisamente algún tipo de receptor que reaccione ante esa fuente y la interprete. Como resultado de tal reacción e interpretación el estado funcional del receptor resulta modificado de un modo que se encuentra relacionado con la forma y organización de la fuente ${ }^{21}$.

La expresión de la información genética permite que un organismo pueda replicarse segundo cánones preestablecidos. En la célula la información necesaria para ello se encuentra codificada en una molécula conocida como ácido desoxirribonucleico - ADN - el cual es transferido a una molécula de ácido ribonucleico mensajero (ARNm) mediante un proceso conocido como transcripción del ADN. Los
ARNm transcriptos son traducidos en proteínas específicas ${ }^{22}$.

Las unidades de información son conocidas como genes, localizadas dentro de los cromosomas y son controladas en su expresión por proteínas reguladoras que se unen en sitios específicos preexistentes en regiones cercanas a zonas codificantes. En los eucariotas (organismos complejos que incluye a los humanos) los genes se componen de vastas regiones codificantes de ADN (exones) separadas de largas regiones de ADN no codificantes (intrones). Esto se descubrió no hace mucho tiempo, en 1977, evidenciándose que en los genes de los eucariotas no se formaban bloques contiguos de secuencias codificadoras de proteínas, sino mosaicos de exones (secuencias de ADN que codifican fragmentos de proteínas) e intercalados con "intrones" (secuencias intercaladas de ADN a menudo externo que no codifica en proteínas) ${ }^{23}$.

La mayor parte del genoma humano se transcribe en ARN, pero sólo el 1.5\% determina proteínas, lo que enseña que el genoma humano está repleto de trascripción inútil o bien que esos ARN no codificados cumplen alguna función desconocida. A diferencia del ADN el ARN es una molécula monohebra, que está presente en las células predominantemente como una cadena simple. Según la función que cumplen existen tres clases principales de ARN. Una de ellas es el ARNm (mensajero), portador de las secuencias de base que codifica la secuencia de aminoácidos de uno o más polipéptidos especificados en un gen o conjunto de genes. Las moléculas de ARNm sirven como molde para la síntesis de proteínas.

Al ponerse en marcha el Proyecto Genoma Humano, uno de los dos grandes grupos de investigación, dirigido por C. Venter, apuntó a la secuenciación en gran escala de ADNc humano, consistente en aislar ARNm producido en diversos tipos de células y obtener a partir de ellos la transcripción inversa del ADNc, que obviamente correspondería a exones de genes que se han expresado en dicha célula ${ }^{24}$. Los científicos que desean obtener una copia limpia del gen pueden interceptar la trascripción de ARNm y determinar su secuencia. Incluso pueden utilizar el ARNm para producir ADNc que tiene la misma secuencia. El ADNc - enseña Jeff Guo - viene a ser como luciría el ADN si fuera depurado de todos los intrones. El no existe de forma natural porque nuestro cuerpo quiere mantener el ADN protegido. Así, el ADNc es una composición artificial a pesar que contiene los mismos datos (secuencias de bases codificantes) que el ARNm, que es una creación natural ${ }^{25}$. 
En consecuencia, la diferencia entre el ADN "genómico" y el ADN "complementario" es que en un caso tenemos un compuesto "en bruto" y en el otro un compuesto "en limpio"; pero ambos contienen exactamente la misma información genética. El "técnico de laboratorio" que menciona la sentencia de la Corte, que obtuvo el ADNc no ha creado absolutamente nada. Por más complicado que resulte el proceso que lleve a su realización y por más tiempo que ello haya insumido, simplemente ha realizado un trabajo de laboratorio no creativo. De allí a una "creación" que lleve a la existencia de una "invención patentable" existe una brecha insalvable.

Adviértase que lo que estaba en discusión en el litigio resuelto por la Corte no era el procedimiento empleado - que por otra parte está en el dominio público - sino el producto o composición de materia (el gen). Pues bien, a nadie se le puede escapar que en ambos casos el producto es el mismo: el de la secuencia de bases codificante y el del gen genómico. Entonces ¿en qué consiste el "invento"? Nadie puede explicarlo racionalmente.

Recuerda acertadamente Jeff-Guo que los genes son básicamente información y la información no puede ser patentada. El cuerpo tiene su propio código, que es un código natural y el cuerpo de forma natural manipula ese código, realizando copias, ediciones y eliminaciones. Las moléculas que prestan esa información, sea ADN o ARN, si existen en forma natural es completamente irrelevante ${ }^{25}$. La Corte expresa en una nota complementaria en el análisis del punto segundo: no expresamos opinión sobre si el ADNc satisface los demás requisitos de patentabilidad ${ }^{17}$. Esto no se corresponde con la importancia de las cuestiones debatidas. Como mínimo el Tribunal debió haber fundado en forma incontrovertible la existencia de una "invención patentable" y consecuentemente los requisitos que la deben acompañar: novedad, altura inventiva y utilidad industrial.

En menos de media página pretendió demostrar la patentabilidad del ADNc, a mi criterio sin lograrlo. Tres argumentos centrales se esgrimen para fundamentar la patentabilidad del ADNc: a) el técnico de laboratorio crea algo nuevo cuando obtiene ADNc; b) el ADNc conserva los exones del ADN natural; pero es distinto del ADN del cual deriva $y ; c)$ como resultado el ADNc no es un producto de la naturaleza y es patentable en virtud del Artículo 101. Veamos ahora la consistencia de este razonamiento.

En primer lugar sostener que el técnico de laboratorio creó algo nuevo al producir ADNc es muy poco convincente. Si se separan en un gen los exones y los intrones, y de tal escisión surge una molécula sólo constituida por los elementos codificantes, lo que ha hecho el "técnico de laboratorio" es - pese a todo el tiempo y a todos los esfuerzos empleados - un trabajo de laboratorio. Si se pudiera calificar de "creación" a todo trabajo de depuración, de segmentación, de purificación, los "técnicos de laboratorio" y aún los "operarios industriales" realizarían una tarea muy creativa, ya que al cabo del día podrían anotar en su haber la creación de diversos productos o composiciones de materia patentables.

Igualmente, observar que el ADNc es distinto del ADN del cual deriva, es una reflexión muy poco convincente. También podría sostenerse que una naranja pelada conserva los gajos de una naranja natural, pero es distinta de la naranja de la cual procede. Cualquier modificación del mundo externo, por mínima que sea, lleva en este esquema a diferenciar el producto original del nuevo. Esto, a los fines de sustentar un derecho de patente, suena como muy extraño.

Por último, sostener que el ADNc no es un producto de la naturaleza y por tanto es patentable, no parece muy atendible. Lo que expresa el referido razonamiento es que todo lo que tiene el sello humano es patentable, por cuanto nos alejamos del mundo natural, que resume lo que está excluido de la protección patentária. Con este criterio se ensancha el campo de lo patentable a límites absurdos.

Al margen de lo dicho, no podemos dejar de considerar que en el caso juzgado se había puesto en tela de juicio el concepto de "invención patentable" y extrañamente la sentencia no dice nada sobre este particular, lo que la privó de un examen que en atención a los términos en que se estableció el debate - resultaba imprescindible. La invención no expresa un concepto indefinido que pueda aplicarse a "cualquier cosa bajo el sol" para justificar el otorgamiento de una patente. La sustancial diferencia entre un invento y un descubrimiento no puede pasarse por alto. Sólo un grave desconocimiento de derecho puede llevar a ampliar, sin justificativo alguno, el campo de lo patentable. Para ingresar en este campo debe existir una creación humana, una elaboración intelectual para solucionar con medios técnicos un problema técnico.

Si bien las leyes de patentes por lo general no definen a la invención, ello no debe autorizar el ingreso a su territorio de cualquier producto de la actividad humana. La patente de invención es algo excepcional que en lo económico desafía al principio general de la libre concurrencia, y en el campo científico al libre uso del stock actual de conocimientos para el 
continuo progreso de la ciencia. Invento y descubrimiento (incluidas aquí leyes naturales o aportes de ciencia básica) se sitúan en terrenos encontrados. La creación técnica se enfrenta al conocimiento que al decir de Stiglitz es un bien público mundial.

Está claro que en el caso de la obtención del ADNc no existió "creación humana" que justifique el pretender una patente de invención. Es necesario destacar que no todo esfuerzo intelectual justifica una protección. La ley ha organizado los derechos privativos y ha subordinado el beneficio a ciertas condiciones: por ejemplo la novedad, la altura inventiva y el carácter industrial en materia de patentes de invención, la originalidad en materia de propiedad literaria y artística. La creación que no responda a las exigencias legales se reputa que pertenece al dominio público, es decir que está a disposición de todos ${ }^{26}$. Al margen de ello, en el caso no se reúnen los universalmente conocidos requisitos objetivos de patentabilidad: novedad, mérito inventivo y utilidad o aplicación industrial.

La sentencia, en una nota al pie, expresa que no expresamos opinión sobre si el ADNc satisface los demás requisitos de patentabilidad ${ }^{17}$. Precisamente, en este caso se imponía señalar en qué consiste la altura inventiva de quien, utilizando conocimientos existentes en el dominio público, obtiene ADNc. Sobre este particular, el Nuffield Council on Bioethics señala: las hipótesis de aislamiento y de clonación de genes involucrados en el descubrimiento de nuevas moléculas de un tipo no producido por el hombre son cuestionables. El hecho que los genes sean esencialmente información genética hace que el tema de la patentabilidad sea muy distinto de aquél que involucra el aislamiento de otros componentes químicos ${ }^{27}$.

En el caso preciso de "invenciones" de genes humanos se trata de productos intermedios, es decir de productos que no sólo carecen de aplicación industrial directa, sino que además son herramientas de investigación de productos susceptibles de aplicación industrial. Los genes y las informaciones que les conciernen (su estructura, su función biológica, su modo de regulación) van a servir de "materia prima" para otras investigaciones que conducirán a medicamentos susceptibles de entrar en fase de producción industrial. La aplicación industrial de genes no se da más que en el caso del gen medicamento que interviene en la terapia génica ${ }^{28}$. En la mayor parte de los casos el gen intervendrá como elemento de un proceso de fabricación de una proteína médica o como medio de conocer mejor el objetivo sobre el cual deben actuar las moléculas terapéuticas o aun los genes sobre sí mismos.

\section{Consideraciones finales}

La Corte Suprema de los Estados Unidos tuvo una magnífica oportunidad de ofrecer al mundo una muestra de imparcialidad y de corrección en un tema muy gravitante no sólo en lo jurídico, sino también en lo social y fundamentalmente en lo ético. Lamentablemente la desperdició y optó por continuar una línea fundada en la protección de los intereses económicos comprometidos. Es que el derecho de patentes se orienta decididamente hacia metas inconcebibles hasta no hace mucho tiempo.

En el mencionado Congreso celebrado en la Universidad de Deusto, Alberto Bercovitz Rodríguez Cano, destacado especialista y autor de la ley española de patentes, al exponer su ponencia destacó: pero no se equivoquen ustedes, el derecho de patentes no es un derecho en el que primen fundamentalmente los principios jurídicos, sino los que priman son los intereses económicos; bastaría que exista un lobby suficientemente fuerte, que las inversiones implicadas que son de miles de millones de dólares, sean suficientemente importantes, para que se cambien principios que lo han regido durante siglos ${ }^{29}$. La visión mercantilista únicamente dirigida por la acumulación de rentas, no sólo afecta al derecho de patentes, sino a la difusión del conocimiento.

A respeto agudamente observan Coriat y Orsi que la transformación del conocimiento en mercancía (bajo la forma de propiedad industrial comercializable y garante de rentas futuras) ha creado las condiciones adecuadas para permitir la entrada de capital financiero en la producción del conocimiento ${ }^{30}$. En el fondo - enseña Gaudrat - la patente es una mercancía más. Nos encontramos en la lógica de la inversión ${ }^{31}$.

En este panorama no es difícil comprender por qué la propiedad industrial está en el centro de las negociaciones de la Organización Mundial del Comercio (OMC) y por qué ejerce tanta presión - llegando a los límites de intimidación - sobre los órganos internacionales y sobre los estados para perseguir la generalización de una propiedad incorporal (no se puede decir más intelectual) atribuible a los inversores ${ }^{31}$. Ingenuamente esperábamos un cambio, pero lamentablemente en este campo los intereses sectoriales son superiores a los principios jurídicos o a los fundamentos éticos. 


\section{Referências}

1. Conseil D’État. Les lois bioéthiques cinq ans après. Paris: Edit. La Documentation Française; 1999. p. 136.

2. Collins F. Lenguaje de la vida: el ADN y la revolución de la medicina personalizada. Barcelona: Edit. Crítica; 2011. p. 303.

3. Franceschi M. Droit et marchandisation de la connaissance sur les gens humains. Paris: Edit. CNRS; 2004. p. 186.

4. Peuscet J. Brevetabilité de la biologie en France en 2006. Paris: Edit. Litec; 2006. p. 78.

5. Peuscet J. Op. cit. p. 80.

6. Collins F. Op. cit. p. 133.

7. Brittany Ngo. Push for "march-in rights" to prevent myriad from asserting patents on cancer test. Intellectual Property Watch. 22 July 2013. [Internet] (acesso 15 jan. 2014) Disponível: http:// www.ip-watch.org/2013/07/22/push-for-march-in-rights-to-prevent-myriad-from-assertingpatents-on-cancer-test/?utm_source=weekly\&utm_medium=email\&utm_campaign=alerts

8. Nuffield Council on Bioethics The ethics of patentability DNA. London: NCB; 2000. p. 26.

9. Tallacchini MC. Umbrales de bioartificialidad en las oscilaciones de la patentabilidad genética. Revista de Derecho y Genoma Humano. 2003; 18:115.

10. Barton J. United States law of genomics and postgenomics patents. IIC, Intellectual Review of Industrial Property and Copyright Law. 2002; 32(7): 779.

11. Kahn A. Et l'homme dans tout ça? Paris: Edit. Nil; 2000. p. 288.

12. Cassier M. La tendence à la privatisation de la recherche génétique et quelques messures de regulation et de correction. In: Laperche B. Proprieté intelectuelle et innovation. Paris: L'harmattan; 2001. p. 127.

13. Bergel SD. Patentes de genes. Revista de Derecho y Genoma Humano. 1998 Enero-Junio; 8:31-59.

14. Bergel SD. Entre la dignidad y el mercado. Revista de Derecho y Genoma Humano. 2002 EneroJunio: $157-80$.

15. Bergel SD. Apropiación de la información genética humana. In: Bergel SD, Minyersky N, organizadores. Genoma humano. Buenos Aires: Edit. Rubinzal Culzoni; 2004. p. 69.

16. Organización de las Naciones Unidas para la Educación, la Ciencia y la Cultura. Declaración Universal sobre el Genoma Humano y los Derechos Humanos. Artículo $1^{\circ}$. Unesco; 1997. (acesso 15 jan. 2014) Disponível: http://portal.unesco.org/es/ev.php-URL_ID=13177\&URL_DO=DO_ TOPIC\&URL_SECTION=201.html

17. Supreme Court of the United States. Association for Molecular Pathology, et al. versus Myriad Genetics, inc., et al. On Writ of Certiorari to the United States Court of Appeals for the Federal Circuit. Argued April 15, 2013, Decided June 13, 2013. Disponível: http://www.supremecourt. gov/opinions/12pdf/12-398_1b7d.pdf

18. Franceschi M. Op. cit. p. 137.

19. France. Institut de France, Académie des Sciences: La brevetabilité du genome, Rapport no 32. Paris: Edit. Tec \& Doc; 1995. p. 12.

20. Cadiet L. La notion d'information en droit français. In: Knoppers B-Cadiet L.: La génétique humaine, de l'information à l'informatisation. Paris: Litec; 1992. p. 47.

21. Jablonke E-LM. Evolución en cuatro dimensiones. Genética, epigenética, comportamiento y variación simbólica en la historia de la vida. Buenos Aires: Edit. Capital Intelectual; 2013. p. 86.

22. Blázquez Fernández E. Concepto de información genética, ácidos nucleicos, estructura del ADN. In: Tresguerres JF, Hernández F-TJA. Biotecnología aplicada a la medicina. Madrid: Edit. Díaz de Santos; 2003. p. 1.

23. Mattick J. Los intrones. Investigación y Ciencia. 2010 primer trimestre; 59 (Temas): 13.

24. Lacadena JR. Genética y bioética. Madrid: Editorial Comillas; 2002. p. 287.

25. Jeff-Guo. The Supreme Court reveals its ignorance of genetics. New Republic 13 June 2013. (acesso 15 jan. 2014) Disponivel: http://www.newrepublic.com/article/113476/supreme-courtgenetics-ruling-reveals-judges-ignorance\#

26. Franceschi M. Op. cit. p. 123.

27. Nuffield Council on Bioethics. Op. cit. p. 28.

28. Franceschi M. Op. cit. p. 162.

29. Bercovitz Rodríguez Cano A. La patentabilidad de los descubrimientos genéticos. In: El derecho ante el Proyecto Genoma Humano. (volumen II). Bilbao: Fundación BBV;1994. p. 173.

30. Coriat $B$, Orsi F. Proprieté intellectuelle, marchés financiers et protection des firms innovantes. In: Frison Roche M-Abella A. Droit et economie de la proprieté intellectuelle. Paris: LGDI; 2005. p. 279. (Collection Droit et Économie).

31. Gaudrat P. Marchandisation. In: Vivant M, director. Proprieté intelectuelle et mondialisation. Paris: Dalloz; 2000. p. 33.

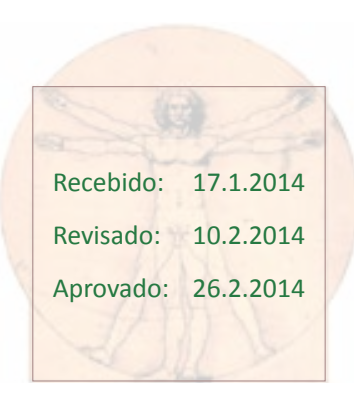

